\title{
Automation, Job content, and Underemployment
}

\section{Marco de Witte and Bram Steijn}

M.C. de Witte \& B. Steijn (2000),'Automation, Job content, and Underemployment', Work, Employment and Society, vol. 14, no. 2, pp. 245-264.

\begin{abstract}
The ongoing skilling debate has already yielded an abundance of contradictory theories, interpretations and empirical contradictions. Based on previous qualitative research in the Netherlands (1992), we have contributed to this debate by introducing the internal differentiation hypothesis. This paper addresses the empirical validity of this hypothesis by analysing data from a representative Dutch panel of 1022 respondents in paid employment. The data show a small overall net upgrading trend. However, automation seems to have different effects for various occupational groups. For blue-collar workers, our findings suggest that a trend of internal differentiation does exist. Next, we examine the consequences (for underemployment and jobsatisfaction) of automation and changes in work content. Although our outcomes do not support our internal differentiation hypothesis, they do show the important effect of autonomy and complexity on feelings of underemployment. The outcomes justify Mottaz' statement that one of the consequences of this underemployment is job dissatisfaction.
\end{abstract}




\section{Introduction}

In the nineties, concepts such as 'the post-industrial economy', 'the knowledge-based, high-skill economy' and 'the knowledge-creating companies' are buzzwords that have already become common articles of faith in the public arena. They are based on optimistic extrapolations and anticipate the growing centrality of theoretical knowledge, continuing expansion of tertiary-level occupations, the increasing eminence of professional and technical classes and a general upgrading of the skills needed for work (Livingstone 1998: 135). As Bell asserted, as early as 1973, workers will require more skills, will become more involved in planning their own work, and will increasingly constitute a professional class.

Since these predictions, there has been a massive amount of research documenting trends in the technical skills of labour in advanced economies. In addition to authors predicting an upgrading trend (such as Blauner 1964; Kerr et al. 1960; Touraine 1955; Woodward 1955), there are also more pessimistic studies that postulate a downgrading trend.. The most notable in this respect is Braverman (1974). The debate has been further complicated by the introduction of the polarisation thesis (Kern and Schumann 1974) and the contingency thesis (Wentink and Zanders 1985).

In the eighties, many authors stressed that the relationship between technological developments and the quality of labour is more ambiguous than many determinist studies in the sixties and seventies proclaimed. According to the 'organisational choice' approach, managers possess different options to implement new technological devices within the production process. Seen in this way, upgrading, downgrading or polarisation effects are potential consequences of the implementation strategy followed by managers. However, Child and Loveridge (1990) found few 
examples of substantial changes in organisational design in response to the technological possibilities offered by information technology. Thus, organisational choices exist in theory, but in practice managers seldom use them. This phenomenon is called 'organisational conservatism'. It brings the discussion about the consequences of automation back to the question whether managerial conservatism in designing organisations leads to upgrading, downgrading or polarisation effects with respect to the skills needed by workers.

Clearly, the debate on technology and the quality of labour has not yet subsided. According to Spenner (1983), data on compositional shifts, aggregate skill levels and case studies are increasingly being read as evidence of a distinct net upgrading trend in technical skill requirements for jobs since 1960. Recent research in the UK supports this claim (Penn et al 1994; Gallie et al 1998). Gallie et al. (1998: 55) have concluded '...the most striking feature of our data is the very extensive upskilling of the workforce'. However, they have also concluded that this process of upskilling varies substantially by occupational class (1998: 56). Especially, semi- and non-skilled manual workers have experienced less skill development.

For the workforce as a whole, it seems safe to conclude that there is substantially more upgrading than downgrading, but there is no evidence for a universal trend. Adler (1992: 8) has pointed out that in the context of a market economy these upgrading tendencies will typically manifest themselves in a somewhat chaotic manner, often leaving pockets of deskilling and lay offs.

In our view, Spenner $(1983,1985,1988,1990)$ made an intriguing observation and an important contribution to the debate. Distinguishing two fundamental dimensions of job content, 'substantive 
complexity' and 'autonomy-control', he observed that studies that define skill as 'substantive complexity' predominantly conclude that an upgrading of job content is going on. However, studies in which skill is measured as autonomy-control indicate downgrading effects. This suggests the possibility of divergent aggregate trends in the two dimensions of skill. Therefore, Spenner has recommended the inclusion of both dimensions in research designs.

Following this suggestion, we analysed the effects on both dimensions of job content in a qualitative analysis of technological changes in four Dutch organisations (Steijn \& De Witte 1992, 1995). Our findings showed that skill changes could not be interpreted in terms of upgrading or downgrading. Practically all the jobs increased in complexity, but this was never accompanied by increasing autonomy. About half of the jobs showed no changes in autonomy, while in the other half, the degrees of freedom for the workers decreased. This led us to formulate the internal differentiation hypothesis. According to this hypothesis, jobs that are directly influenced by processes of automation display increasing complexity, while at the same time the level of autonomy of these workers decreases. Thus, automation seems not only to have differential effects across the various occupational categories among jobs, as suggested by Vallas (1988: 171), it also has contradictory effects within the job content along the two dimensions of autonomy control and substantive complexity. This conclusion gives empirical support to Spenner's 'contradictory skill shift hypothesis' (1988: 159).

As the internal differentiation hypothesis is based on qualitative research, further tests to determine its general applicability are needed. In an earlier article, we tried to do this with a secondary analysis of a data set consisting of 242 metalworkers from 31 companies (Steijn \& De Witte 1993). In this analysis, we indeed observed processes of internal differentiation: the 
complexity and autonomy within jobs in the metal industry developed independently. However, the analysis did not entirely support the internal differentiation hypothesis formulated above. Although the complexity of jobs that were more automated increased, autonomy remained almost stable in contradiction to the hypothesis.

The fact that the jobs analysed were only partly automated can explain this finding. In our original qualitative research we analysed jobs in which most of the tasks were executed with the support of fully automated devices. The follow-up research suggested the existence of a different form of internal differentiation in which increasing complexity is related to an almost constant level of autonomy. This form could be typical for technically subordinate jobs, such as those of metal workers (machinists, welders, etc.), in which the automated devices form only a part of the total set of tools and instruments wielded. Based on the above considerations, the question remains whether and to what extent processes of internal differentiation exist.

As previously mentioned, Bell anticipated a growing centrality of theoretical knowledge. Regardless of whether this is valid or not, the populations of the advanced industrial societies have achieved unprecedented levels of formal qualifications, which are still increasing rapidly. In the light of the skilling debate, the crucial question is to what extent workers can actually apply these skills. Recently, Livingstone wrote an intriguing book on the so-called education-jobs gap. This gap refers to the discrepancy between work-related knowledge and the opportunities to apply this knowledge in interesting and fairly remunerated work. His basic argument is that most workers continually gain much more work-related knowledge than they will ever have a chance to use in their job. He asserts that since the 1960s in the US and in Canada [but also in the 
Netherlands (Asselberghs et al. 1998)], the gradual net upgrading of jobs has been exceeded by the rapid expansion of the educational qualifications of the workforce.

According to Livingstone, 'underemployment' has clearly become a problem. In his book he distinguishes six different dimensions of underemployment. To us, two of these in particular are important: the credential gap and the performance gap. The credential gap refers to the match between the educational attainments of job holders and the credentials required for job entry. Provided one has a job, the performance gap refers to the correspondence between the performance requirements and the skills acquired through schooling. In more formal terms, the performance gap indicates 'the equivalencies between technical skills required for job task performance and the amount of schooling needed to ensure that these skills have been acquired' (Livingstone 1998: 78).

In our view, another aspect of underemployment, one not mentioned by Livingstone, is also of importance. Although he points to what he calls 'icebergs of informal learning' and tries to include all aspects of the phenomenon of underemployment, he ignores the aspect of skill formation. We call this 'the development gap'. This development gap refers to the learning capabilities of the workforce. Does a job or workplace stimulate formal and informal (life-long) learning activities? Besides using qualifications (an aspect incorporated in both other gaps), performing jobs can also stimulate the development of new potential(s).

Underemployment is clearly related to the debate about upgrading or deskilling. In our qualitative study (Steijn \& De Witte 1992), we found that increasing complexity in jobs is usually accompanied by higher demands for educational qualifications. To explain this rise in qualifications required, our respondents themselves pointed to the increasing complexity of the 
jobs they performed. Often, although not always, this rising complexity is explained as a direct effect of technological developments. At the same time, automation leads to standardised and routinised work that robs workers of the chance to learn on the job. During work it becomes impossible to develop new skills or to acquire more advanced work experience as workers become deprived of their ability to think, figure out and discover.

In accordance with Van Weenen (1980), we observed both rising demands for educational qualifications and, simultaneously, decreasing autonomy and possibilities for skill formation. Although the educational entry requirements for (some) jobs are rising, due to increasing complexity, there are fewer possibilities to use these qualifications because of lower autonomy. In this sense, the capacities of workers are underutilised. According to Mottaz (1984), one of the consequences of this underemployment is work dissatisfaction. His argument is based on the notion that education tends to increase work expectations that cannot be met by relatively lowlevel jobs and, hence, contributes to job dissatisfaction.

The conceptual framework for this article combines concepts from the skilling debate, studies on underemployment, and overall job satisfaction and focuses on their interrelationships. This is illustrated in figure 1.

****** Here about Figure $1 \quad * * * * *$

To analyse whether the relationships assumed in this figure are correct, this paper addresses the following research questions. 
1. How is the process of automation related to the autonomy and complexity of the job content of Dutch workers? Do processes of internal differentiation exist and do the kind of jobs and their degrees of automation influence these processes?

2. How is the content of jobs related to the opportunities for workers to utilise their qualifications and skills?

3. How are these opportunities related to overall job satisfaction?

To answer these research questions we investigated whether an internal differentiation process really existed. To get an idea of the specific contexts in which this process could arise, several occupational groups were differentiated. Subsequently, we examined the possibilities workers had to make full use of their qualifications, skills and experiences in jobs. For this purpose, we examined three different utilisation gaps: the credential gap, the performance gap and the development gap. Finally, these utilisation gaps were related to job satisfaction. In the analysis, we used both bivariate as well as multivariate (regression) analyses.

\section{Methods: Design and Measurement}

Design

Ideally, our research question would require a longitudinal design. This would permit the effect of automation on the job content to be determined by comparing this content before and after automation. Since longitudinal data were not available, we had to use a cross-sectional design by varying the degree to which jobs were affected by automation. In this way, we compared the job 
content of roughly similar jobs with different degrees of automation. We assumed that these different degrees of automation indicated the effects of the process of automation over time. This assumption is debatable, but considering the available data it was the best possible solution.

To answer the key research questions we analysed data gathered at the end of 1994. The data upon which this study was based were obtained from the Stichting Telepanel. This panel consists of people who have a personal computer at their disposal from the 'Stichting Telepanel'. In return for the free (private) use of this computer these people have to fill in a weekly questionnaire. Researchers use this facility to obtain reliable data in a quick and efficient way. We submitted a questionnaire to a panel of 1022 respondents. According to the organisers of the Telepanel, this panel was representative of the total Dutch population.

In the questionnaire, questions were directed at panel members with a paid job. The questions asked were related to the content of their jobs, the effects of automation on the job content and the respondents' attitudes towards their jobs in terms of job satisfaction, career opportunities, feelings of underemployment, and so on. Out of 1022 respondents interviewed, 654 were male and 368 were female. The mean age was 39 years old. Regarding our research questions, the following variables were relevant: the degree of automation, autonomy, complexity and the kind of jobs executed. Furthermore, the variable 'internal differentiation' was important as such, as of course were variables indicating the opportunities for workers to utilise their qualifications and skills, such as the credential gap, the performance gap and the development gap. The overall dependent variable was job satisfaction.

\section{Measures}


Degree of automation. As mentioned earlier, we used a cross-sectional design. Therefore, the degree of automation of the jobs within each job cluster had to be determined. In the analysis, we compared the autonomy and the complexity of jobs that were affected by automation to varying degrees. Two questions in our survey were used to determine the degree of automation. Firstly, one question checked whether the respondents worked with any automated devices at all ${ }^{\mathrm{D}}$. The respondents who answered 'yes' were then asked how many hours a week they worked with these devices. Subsequently, both answers were combined to form a new variable 'degree of automation'. This variable consisted of three categories: a group of respondents who did not work with automated devices at all (32\% of all respondents), a group of respondents (43\%) who worked part of the time with these devices (i.e., who said that they worked $50 \%$ or less of their working time with these devices), and a group of respondents who worked a substantial part (more than $50 \%$ ) of the time with these devices ( $25 \%$ of all respondents).

This (nominal) variable could not be used in regression analysis. Therefore, we constructed two dummy variables. The first dummy variable differentiated workers who did not work with automated devices from workers who did. The second dummy variable differentiated workers who worked a substantial part of the time with automated devices from workers who used them only part of the time or not at all.

Job content: autonomy and complexity. The definition and measurement of 'job content' is not straightforward. As mentioned in section 1, Spenner $(1985 ; 1992)$ has suggested that qualitative and quantitative studies indicate at least two fundamental dimensions of skill: 'substantive complexity' and 'autonomy-control'. Substantive complexity refers to 'the level, scope and 
integration of mental, interpersonal, and manipulative tasks in a job' (Spenner 1985: 829). The distinction between manipulative, interpersonal and mental tasks refers to the classic distinction between jobs that primarily deal with things, with people or with data. In addition to complexity, Spenner distinguishes 'autonomy-control' as the second dimension of skill. There is no consensus on the definition of autonomy, but we agree with him that it refers to the discretion available in a job to initiate and conclude action, to control the content, the manner and the speed with which a task is done (1985: 829).

To measure 'autonomy' and 'complexity' we used an instrument that is popular in the Netherlands, the so-called NOVA-WEBA instrument (Houtman et al. 1994). This instrument measures 'autonomy' with a scale consisting of nine items. The reliability of this scale was assessed by Cronbach's alpha, which produced a reliability coefficient of .78 . To determine the degree of complexity, eleven out of the original fourteen items were used ${ }^{3}$. These items also formed a reasonable scale. Cronbach's alpha yielded a reliability coefficient of .74.

Internal differentiation. In accordance with our research question, we were not really interested in autonomy and complexity as such, but rather in the relationship between them. According to our internal differentiation hypothesis, automation would lead to an increase in the complexity and a decrease in the autonomy of a job. A variable indicating internal-differentiation was constructed as follows. First, the two scales of complexity and autonomy were dichotomised (based on zscores) in high and low scoring categories. The level of autonomy or complexity was defined as 'low' if the standardized z-score on the variable autonomy or complexity was less than ' 0 '. The level was defined as high if the z-score was equal to or higher than ' 0 '. In order to analyse the 
mutual relationship between autonomy and complexity, we constructed a variable distinguishing four categories: first, workers with a job with low levels of autonomy and complexity (143 respondents); second, workers with a job with a high level of autonomy and a low level of complexity (236 respondents); third, workers with a job with low autonomy and high complexity (238 respondents); finally, workers with a job with both high autonomy and high complexity (403 respondents). The third category was especially important for studying the existence of an internal differentiation process. In this category a high level of complexity was combined with a low degree of autonomy. If the internal differentiation hypothesis were correct, it would imply that, according to processes of automation, the number of workers within this third category would increase. We investigated whether this was true in a bivariate analysis. In the regression analysis, we introduced a dummy variable for this special category: respondents with an internally differentiated job position $(=1)$ or without $(=0)$. This provided the opportunity to include the variables 'autonomy', 'complexity' and 'internal differentiation' simultaneously in the analysis.

Occupational groups. Of course, our respondents occupied a great variety of jobs. In accordance with our cross-sectional design, clusters of roughly similar occupations were therefore created. Based on the survey data, six clusters were differentiated. To do so, we combined the class schemes of Goldthorpe (1980) and Esping-Andersen (1993). At the root of the classification lies the assumption that occupations in the same category share a similar work and market situation. In agreement with Esping-Andersen, we believe that professionals have to be treated as a distinct group of workers ${ }^{1}$. The six clusters are given below:

1) Subordinate white-collar workers. This cluster, consisting of 264 workers, included several 
clerical occupations without supervisory tasks.

2) White-collar supervisors. This cluster contained 158 workers.

3) Subordinate blue-collar workers. This cluster (212 workers) included both skilled and unskilled workers.

4) Blue-collar supervisors. This cluster contained 62 workers.

5) Subordinate (non-supervisory) professional workers. In this and the following category, jobs were included that, according to Esping-Andersen (1993), are characteristic of a 'post-industrial' class structure. Containing 245 workers, this cluster included lawyers, scientists, computer workers, teachers, and nurses.

6) Supervisory professional workers. This cluster (79 workers) contained jobs that are similar to cluster five, but the job occupants performed supervisory tasks.

Utilisation gaps. To measure the degree to which workers use their potentials, we constructed three variables. Subsequently, we constructed variables to measure the credential gap, the performance gap and the development gap. The credential gap entails that employers have increased the educational entry requirements for some jobs beyond the levels of knowledge actually needed to perform them. In the literature, concepts such as 'the credential society' and especially ‘credential inflation' refer to this. The fundamental question is how closely educational attainments of job holders match the credentials required for entry into their current job (Livingstone 1998). We measured this variable by subtracting the actual educational level attained by the respondent with the entry credential requirements asked for by the employer (reported by the respondent him/herself; both educational variables consisted of five hierarchical levels). The 
scores on this variable ranged from between -3 (for workers who were very underqualified) and +3 (highly over-qualified workers). As we were only interested in 'overqualified' workers (i.e. workers who had a higher educational level than required) we recoded this variable: we gave all underqualified workers (81\%) a score of ' 0 ' on this variable.

The performance gap is not related to job entry credentials but is about using qualifications once one has a job. The crucial question here is to what extent workers are able to use the skill level they have attained in the actual performance of their jobs. To measure the degree of correspondence between the performance requirements and the skills acquired we asked our respondents the following question: Does your job challenge all your skills and knowledge? Possible answers ranged between 1 'never' and 4 'always'. The initial average score was 3.06, so on average the respondents felt that their jobs regularly fulfilled their potential. In the regression analysis, we recoded this variable in such a way that a higher score indicated a higher performance gap.

The development gap denotes the possibilities for workers to attain new skills while performing their jobs, in other words, learning-by-doing. The development gap focuses, in other words, on skill formation as the product of on-the-job training. The variable 'development gap' was measured by averaging the responses of workers to four items. The reliability of this scale was assessed by Cronbach's alpha which produced a reliability coefficient of .68 (not very high, but acceptable). ${ }^{6}$ The average score on this scale for all respondents was 2.6 , which indicated that most workers judged the opportunities possibilities for skill formation as being favourable. Like the preceding variable, this one was also recoded in such a way that a higher score indicated a higher development gap. 
Job satisfaction. Our overall dependent variable job satisfaction was defined as the worker's affective response resulting from an evaluation of various aspects of the work situation (Locke 1969; Mottaz 1984; 1987). Job satisfaction is a function of both work values and work rewards. Work rewards refer to the intrinsic and extrinsic benefits that workers receive while doing their work (Herzberg 1966). Work values refer to what workers want, desire, or seek to attain in a job. Such values are standards that the individual uses to assess or evaluate the work situation (Locke 1969). Although often done, such a conglomerate variable is difficult to measure directly with one general question ('Generally speaking, are you satisfied with your job'?) For that reason we measured this variable with eight commonly used items. These items formed a scale from 1 to 8 with a reliability coefficient of .76 (Cronbach's alpha). A low score on the job satisfaction scale meant that the respondent was not satisfied with his/her work and a high score indicated a high degree of job satisfaction. The average score was 6.3 , which indicated that in general the respondents were rather satisfied with their jobs.

\section{Analysis}

\section{The Internal Differentiation Hypothesis}

According to the internal differentiation hypothesis, jobs become more complex as the level of autonomy decreases. The following analysis - with the mutual relationship between autonomy and complexity as the dependent variable - illuminates this relationship between automation and the 
content of jobs. To start with we focused on the overall association between the degree of automation of the job and the job content. In the following table (and subsequent ones) LA means 'low autonomy', HA ‘high autonomy’, LC ‘low complexity’, and HC ‘high complexity’.

The association between the degree of automation and the mutual relationships between autonomy and complexity was slight, but statistically significant. Overall, it appeared that an increasing degree of automation was associated with a decrease in the proportion of jobs in the category low autonomy/low complexity and an increase in the proportion of jobs in the category high autonomy/high complexity. Therefore, it seemed that a net upgrading trend was associated with increasing automation. This trend was especially visible when non-automated jobs were compared with partly automated jobs. The differences between the categories 'partly' and 'substantially' automated were smaller.

Looking specifically at the third category of jobs characterised by high complexity and low autonomy, it became clear that a dominant process of internal differentiation did not exist: the proportion of internally differentiated jobs even decreased slightly (from $26 \%$ to $22 \%$ ) once automation had taken off.

We also investigated this for the various occupational groups distinguished in the former section. An earlier analysis had shown that the association between the degree of automation and internal differentiation was (much) stronger for subordinate workers than for supervisory workers (for more information: Steijn \& De Witte 1998). In fact, for supervisors there was no relationship 
between the degree of automation and the level of complexity. Probably too many intervening factors complicated the situation for supervisors. We therefore decided to focus the second half of our analysis on subordinate workers. This implied a reduction in the total number of respondents from 1022 to 722 , of which 407 were male (56\%) and 315 female (44\%). These workers were divided into three different occupational groups: 212 blue-collar workers (29\%), 264 white-collar workers (37\%) and 246 professionals (34\%).

For all three occupational groups, the association between the degree of automation and the mutual relationship between autonomy and complexity was statistically significant. Table 2 shows that, with respect to white-collar workers, an increasing degree of automation led to an expansion of the category high autonomy/high complexity. Particularly the categories low autonomy/low complexity and low autonomy/high complexity diminished in size. Thus, an upgrading of the job content of white-collar workers is apparently associated with automation.

This conclusion cannot be reached for blue-collar workers. Although the category high autonomy / high complexity increased in size proportioned to that of white-collar workers, the same held true for the category low autonomy/high complexity. Moreover, the latter category was even the most common one for partly and substantially automated blue-collar jobs. Therefore, it appears that for many blue-collar workers automation is associated with a process of internal differentiation.

The results for professionals were noteworthy: an increasing degree of automation was 
associated with a dramatic proportional growth in the category high autonomy/high complexity (from $29 \%$ to ultimately $62 \%$ !). An existing internal differentiation (that could be seen within the non-automated jobs) decreased when the degree of automation increased. This leads to the conclusion that for professionals, just as for white-collar workers, automation is associated with an upgrading of the job content. ${ }^{8}$

Interestingly, these results are very similar to the findings of Gallie et al. (1998) mentioned in the introduction. Although their conceptualisation of the skill concept differs, they have also found that for most workers a process of upskilling is taken place. According to their findings semi- and unskilled manual workers are a notable exception. Although we have not made a distinction between skilled and less skilled manual workers, it is striking that our findings are also suggesting different changes in job content for manual workers compared to other occupational classes.

It must be stressed that our conclusions alone do not support a technological-deterministic interpretation. After all, it is not clear from our analysis whether the changes in autonomy or complexity were solely the result of the introduction of automated devices. Surely, these changes could also have been influenced by the implementation strategies of managers and other contingencies. Technology is of course not the only factor that contributes to the design of workplaces and job content. Pressure for better integration of product and process designs, new competitive conditions and market demands, demographic trends and cultural shifts also contribute. 


\section{Utilisation Opportunities}

To answer our second research question we needed to analyse the workers' opinions about their possibilities of using their skills in the workplace. As outlined in the introduction, we expected that automation and the process of internal differentiation would particularly diminish the possibilities for workers to exploit their potentials, resulting in less job satisfaction.

To analyse whether this was true, we first executed several regression analyses with the three 'utilisation gaps' as dependent variables. In these analyses the following independent variables were included: personal characteristics of the workers (gender, age, educational level), the process of automation (automated time), occupational group (blue-collar worker, professional) and the content of the job (the level of complexity and autonomy, internal differentiation). The results of these analyses are shown in table 3. As outlined in the measurement section, in each analysis a higher score on the dependent variable meant a larger 'gap'.

In all three analyses, the independent variables could explain a reasonable part of the variation in the dependent variable. The major hypothesis lying behind our analysis was that workers with jobs that were internally differentiated would particularly experience the utilisation gaps. The results clearly falsified this hypothesis. There was no significant effect of the variable internal differentiation (on the credential or the development gap). There was a small effect on the performance gap. However, the direction of this effect was different than expected: workers in an internally differentiated job perceived a lower performance gap than workers in other jobs. 
Although they do not support our expectations, the results are worth discussing. Most notable is the fact that for all three gaps, both autonomy and complexity played an important part in explaining variance. Workers with higher autonomy and higher complexity perceived a lower credential gap, a lower performance gap, and a lower development gap. This confirmed the idea that both variables were important dimensions of the job content. Interestingly, when we compared the beta-coefficients, complexity seemed in each case substantially more important than autonomy. This could explain why internal differentiation was not associated with perceiving an underemployment gap: possibly, when evaluating their underemployment situation, workers in an internally differentiated job weigh the complexity of their job higher than their degree of autonomy.

The strong effect of educational attainment on the credential gap was partly an artifact: one has to be higher educated to experience such a gap in the first place. Nevertheless, it is important to note that higher educated workers did perceive a credential gap more often. It is also worth noting that education was positively correlated with the perception of the performance gap: higher educated workers perceived such a gap more often. This is consistent with the findings of Livingstone (1988: 83).

The finding that younger workers more often perceive a performance gap is also consistent with Livingstone. Interestingly enough, however (older workers) more often perceived a development gap, which meant that they experienced fewer possibilities for skill formation. This confirms a finding of our earlier qualitative research (1992): for many jobs the statement 'one year of learning, twenty years of routine' seems to hold true (Steijn \& De Witte 1998).

Given earlier research, one would have expected bigger underemployment gaps for 
women (compare Livingstone 1988: 73). This, however, was not the case. Other variables being constant, there were no differences between men and women with respect to their evaluation of possible underemployment of their skills.

With respect to occupational groups, there was only a notable effect on the credential gap. Blue-collar workers recognised more credential underemployment than other workers, and professional workers less. Therefore, blue-collar workers perceived a discrepancy between their current job level and the educational entry requirements for their current job. At the same time, however, they did not (more often) perceive a performance or a developmental gap. This meant that regardless of their occupational group, workers had a similar perception of the way they could use their potentials and the chances their job offered for new skill formation.

Finally, the modest effect of automation should be mentioned. There was no direct effect (on either the developmental gap or the performance gap) of either of the dummy variables indicating the degree of automation. There was only a small effect of the dummy indicating whether or not automated devices were worked with. As for the credential gap this was larger for workers working without automated devices than for other workers. This suggests that more automation is associated with a decrease in this gap.

Of course, the overall effect of automation cannot be neglected. Besides a direct effect on the underemployment gap it also had an indirect effect. As we have seen, the results mentioned previously suggested that automation was associated with increasing autonomy and complexity. This meant that given the negative association of both autonomy and complexity with the dimensions of the underemployment gap, there was also a negative indirect effect of automation on workers' perception of these gaps. 
Although the overall effect of automation should be positively evaluated, it is also clear that in those cases where automation is associated with decreasing autonomy (i.e. the pockets of deskilling mentioned by Adler), the automation process will have negative consequences. In those cases, automation will lead to more standardized and routinized jobs that rob workers of the possibilities to learn on the job (compare Hirschhorn 1984). However, for the majority of work situations this was not the case according to our data.

\section{Job Satisfaction}

To answer our third research question, we tested the hypotheses that credential, performance and development underemployment are inversely related to job satisfaction. After all, as Mottaz (1984) stated, one of the alleged consequences of underemployment is work dissatisfaction. We performed a two step regression analysis that is presented in table 4 .

******

Here about table 4

******

The results are interesting as they show the importance of the underemployment gap for job dissatisfaction (as we had expected from our conceptual framework). In the first step of the analysis, four variables were positively associated with a higher job satisfaction: older workers, lower educated workers and workers with a job with higher complexity and autonomy were more satisfied with their jobs. In the second step, after the introduction of the three dimensions of underemployment, the effects of educational attainment, autonomy and complexity disappeared. In their place, there were rather strong effects of the performance and the development gap on job 
satisfaction: workers who perceived such a gap were clearly more dissatisfied with their jobs.

This of course implies that the effects of autonomy and complexity on job satisfaction were only indirect, and mediated by the chances workers had to utilise their skills and learn new things. It is interesting that educational attainment also had an indirect effect. It underscores a point made by Mottaz (1984: 998) who suggested that given equal levels of intrinsic rewards, more educated workers tend to be considerably more dissatisfied with their work than their less educated counterparts. Mottaz' interpretation is formulated as follows: 'the fact that education may lead to dissatisfaction in work by not producing the expected intrinsic rewards suggests that the problems of overeducation and underemployment must be taken seriously' (1984: 1001). Our results seem to confirm this interpretation.

\section{Conclusion and Discussion}

In this article we have tried to answer three questions. The first question addressed the empirical validity of the internal differentiation hypothesis. Clearly, our results show that an overall process of internal differentiation does not occur. When compared to non-automated jobs, automated jobs are characterised both by higher levels of complexity and autonomy.

In more detail, our analysis shows that automation seems to have different effects for blue-collar, white-collar and professional workers. For white-collar and professional workers the effects can be interpreted as net upgrading, although this effect is much stronger for professionals. However, this is not the case for blue-collar workers. For many blue-collar workers automation is associated with an internal differentiation process (see also Steijn \& De Witte 1998). This conclusion supports the finding presented by Gallie et al. (1998) that the process of upskilling 
varies by occupational class.

Adler's analysis (1992) suggests an interpretation for the different effects automation has for various occupational groups. Reviewing the (fourth generation) literature on the relationship between automation and the quality of labour, he recognises a net upgrading trend, 'often leaving pockets of deskilling'. Our findings confirm a net upgrading trend for the Netherlands (see also Huijgen 1989; Asselberghs et al. 1998). Within this general trend, the developments for bluecollar workers can be interpreted as a pocket of deskilling, not because of decreasing levels of complexity and autonomy, but due to increasing internal differentiation.

Unfortunately, we are not able to answer the question why automation has different effects for these three occupational groups. A plausible interpretation is that the automation policy followed by managers has divergent effects on the various job categories. It could be that the structures of power within white-collar or professional work settings compared to blue-collar work settings imply different managerial strategies with respect to the implementation of new technology. In this respect we refer to findings in a study of Zuboff (1988). According to this study, managers are able to deal with organisational innovation in two ways. The first is a strategy of automation that means rationalising work by the standardisation and routinisation of work processes, while decreasing the dependence on human skills. A second strategy is to exploit the technology's information capacity. This strategy '..increases the explicit information content of tasks and sets into motion a series of dynamics that will ultimately reconfigure the nature of work and the social relationships that organise productive activity' (1988: 10). Regarding our data, it seems worthwhile to study the possibility that in Dutch industrial work settings, managers follow a conscious 'strategy of automation' in contrast to managers in white-collar or professional work 
settings. However, further research is needed to answer the question whether or not this interpretation is valid.

The assumption behind the second research question was that processes of automation would change the content of jobs and the degree to which jobs enable the utilisation of the skills and knowledge of the workers. Our results show strong associations between the complexity of and autonomy within jobs and the three different 'utilisation gaps' we distinguished. This supports the view that these indeed are crucial dimensions of the job content. However, we were not able to find a relationship between the experience of internal differentiation and feelings of underutilisation. It could be that this is an effect of our finding that complexity is more important than autonomy with respect to the experience of feelings of underutillisation.

To answer the third and final research question, we scrutinised the relationship between the three different utilisation gaps and overall job satisfaction. According to our results, Mottaz' statement that job dissatisfaction is related to underemployment is well founded. Variables such as 'automation', 'internal differentiation', 'complexity' and 'autonomy' are relevant but have only indirect effects on job satisfaction. These variables are related to the performance and development gap, which, together with age, are strong determinants of satisfaction.

The importance of these effects implies that policymakers should pay less attention to possible 'skill deficiencies' of the current workforce. Indeed, there is little evidence of any general and persistent technical skill deficit among employed workers (Asselberghs et al. 1998; Livingstone 1998). Not a lack of education but the lack of decent jobs is the obvious basic problem. Those who promote human resource management in organisations should pay more attention to the 'education-jobs gap'. After all, our research indicates that work situations that 
effectively exploit the knowledge and skills available are definitely needed.

\section{References}

Adler, P.S. (1992) 'Introduction', in: P.S. Adler, (ed.) Technology and the future of Work, New York/Oxford: Oxford University Press, 3-14.

Asselberghs, K., R. Batenburg, F. Huijgen and M. de Witte (1998) De kwalitatieve structuur van de werkgelegenheid in Nederland. Deel IV. Bevolking in loondienst naar functieniveau: ontwikkkelingen in de periode 1985-1995, Den Haag: OSA.

Assimakopolou, Z., G. Esping-Andersen and K. van Kersbergen (1992) Post-industrial Class Structures: Classifications of Occupations and Industries (United States, Germany, Sweden, Canada), San Domenico: EUI Working Paper no 92/18.

Bell, D. (1973) The Coming of Post-Industrial Society, New York: Basic Books.

Blauner, R. (1964) Alienation and freedom: The factory worker and his industry, Chicago: The University of Chicago Press.

Braverman, H. (1974) Labor and Monopoly Capital. The Degradation of Work in the Twentieth Century, New York/London: Monthly Review Press.

Child, J. and R. Loveridge (1990) Information Technology in European Services. Towards a Microelectronic Future, Oxford: Oxford University Press.

Esping-Andersen, G. (ed.) (1993) Changing Classes. Stratification and Mobility in Post-Industrial Societies, London.

Herzberg, F. (1966) Work and the nature of man, Cleveland: World.

Houtman, I., A. Bloemhof, S. Dhondt, and C. Terwee (1994), Weba en Nova-Weba in relatie tot gezondheid en welbevinden van werknemers, Leiden: TNO.

Huijgen, F. (1989) De kwalitatieve structuur van de werkgelegenheid in Nederland, deel III, Bevolking in loondienst en functiestructuur in 1977 en 1985, Den Haag: OSA.

Gallie, D., M. White, Y. Cheng, and M. Tomlinson, Restructuring the employment relationship, Oxford: Clarendon Press.

Kern, H. and M. Schumann (1974) Industriearbeit und Arbeiterbewusstsein, Frankfurt am Main: Europaïsche Verlanganstalt. 
Kerr, C., J.T. Dunlop, F. Harbinson, and C.A. Myers (1960) Industrialism and Industrial Man: The Problems of Labor and Management in Economic Growth, Cambridge.

Livingstone, D.W. (1998) The Education-Jobs Gap. Underemployment or Economic Democracy, Boulder Colorado: Westview Press.

Locke, E.A. (1969) 'What is job satisfaction?', Organizational Behavior and Human Performance, 4, 309336.

Mottaz, C. (1984) ‘Education and Work Satisfaction', Human Relations, 37, 11, 985-1004.

Penn, R., Rose, M., and J. Rubery, Skill and occupational change, Oxford: Oxford University Press

Spenner, K.I. (1983) 'Deciphering prometheus: temporal change in the skill level of work', American Sociological Review, 48, 824-837.

Spenner, K.I. (1985) 'The upgrading and downgrading of occupations: Issues, evidence, and implications for education', Review of Educational Research, 55, 2, 125-154.

Spenner, K.I. (1988) 'Technological change, skill requirements, and education: The case for uncertainty', in: R.M. Cyert and D. C. Mowery (eds.), The impact of technological change on employment and economic growth, Cambridge, 131-184.

Spenner, K.I. (1990) 'Skill: Meanings, methods and measures', Work and Occupations, 17, 4, 399-421.

Steijn, A.J. and M.C. de Witte (1992) De Januskop van de industriële samenleving. Technologie, arbeid en klassen aan het begin van de jaren negentig (The Two Faces of Industrial Society. Technology, Labor and Class in the Nineties), Alphen aan den Rijn: Samsom Bedrijfsinformatie ( $\mathrm{PhD}$ thesis).

Steijn, B. and M. de Witte (1993) 'De interne differentiatie hypothese nader onderzocht. De invloed van automatisering op complexiteit, autonomie en arbeidsbeleving', Tijdschrift voor Arbeidsvraagstukken, 9, 3, 253-262.

Steijn, B. and M. de Witte (1995) 'Technology and the quality of labour: The internal differentiation hypothesis', in: Economic Society of Thessaloniki, Proceedings of the 4th International Congress 'New Technologies in Business and Economics', Thessaloniki: University Studio Press, 119-141.

Steijn, A.J. and M.C. de Witte (1998) 'Chaotic patterns in the upgrading of labour. A test of the internal differentiation hypothesis', in: L. Sanz-Menéndez, C.E. García (eds.), Management and Technology, Brussel: European Community, Office for Official Publications of the European Communities, 529-544.

Vallas, S.P. (1988) 'New technology, job content, and worker alienation: A test of two rival perspectives', Work and Occupations, 15, 2, 148-178. 
Vallas, S.P. (1990) 'The concept of skill: a critical review', Work and Occupations, 17, 4, 379-398.

Weenen, B. van (1980) Computer, arbeid en organisatie. Een evaluatie van sociale en organisatorische aspecten rond automatisering, Alphen aan den Rijn: Samsom.

Wentink, T. and H. Zanders (1985) Kantoren in actie. Een onderzoek naar kantoorautomatisering en de gevolgen voor kantoorarbeid en kantoororganisatie, Deventer: Kluwer.

Woodward, J. (1958) Management and technology, London.

Zuboff, S. (1988) In The Age of The Smart Machine. The Future of Work and Power, New York. 
Figure 1. Conceptual framework

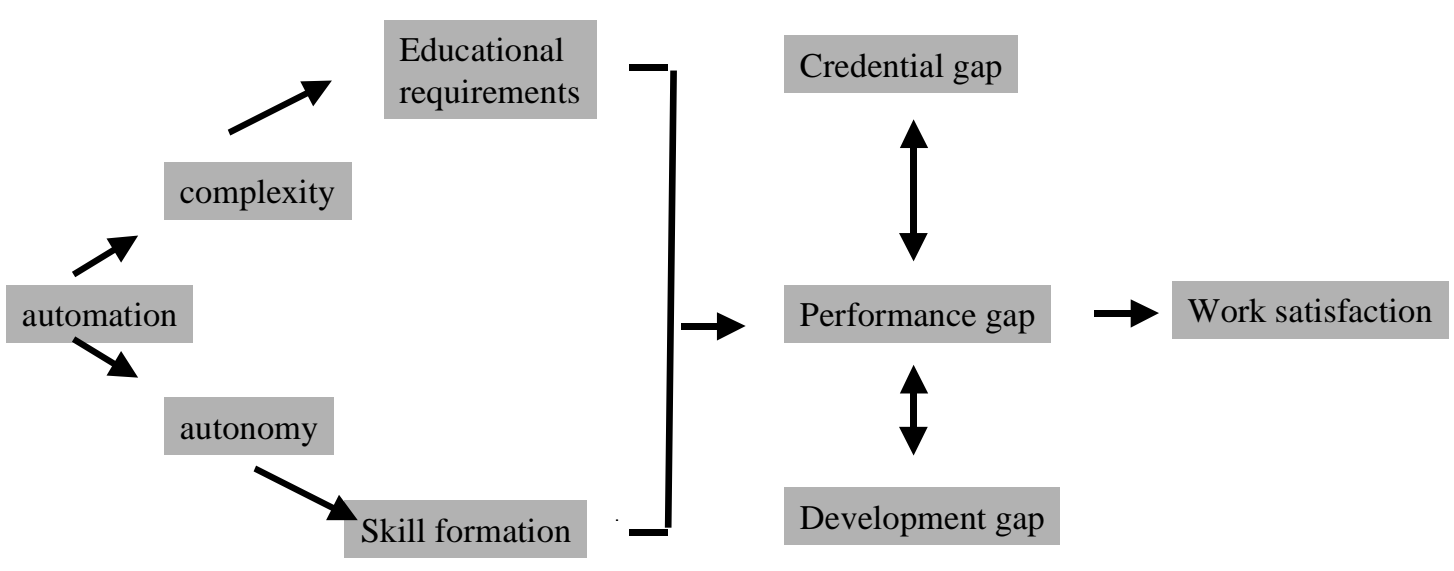


Table 1 Mutual relationships between autonomy and complexity by degree of automation (in \%)

\begin{tabular}{|l|l|l|l|l|}
\hline $\begin{array}{l}\text { Autonomy / } \\
\text { Complexity }\end{array}$ & $\begin{array}{l}\text { Non } \\
\text { Automated }\end{array}$ & $\begin{array}{l}\text { Partly } \\
\text { automated }\end{array}$ & $\begin{array}{l}\text { Substantially } \\
\text { Automated }\end{array}$ & Total \\
\hline & & & & \\
\hline LA LC & $22 \%$ & $8 \%$ & $14 \%$ & $14 \%$ \\
\hline HA LC & $27 \%$ & $23 \%$ & $20 \%$ & $23 \%$ \\
\hline LA HC & $26 \%$ & $23 \%$ & $22 \%$ & $23 \%$ \\
\hline HA HC & $26 \%$ & $46 \%$ & $45 \%$ & $40 \%$ \\
\hline & & & & \\
\hline N $=1022$, Cramer's V $=.16, p<0.001$ &
\end{tabular}


Table 2 Mutual relationships between autonomy and complexity by degree of automation for occupational groups (in \%)

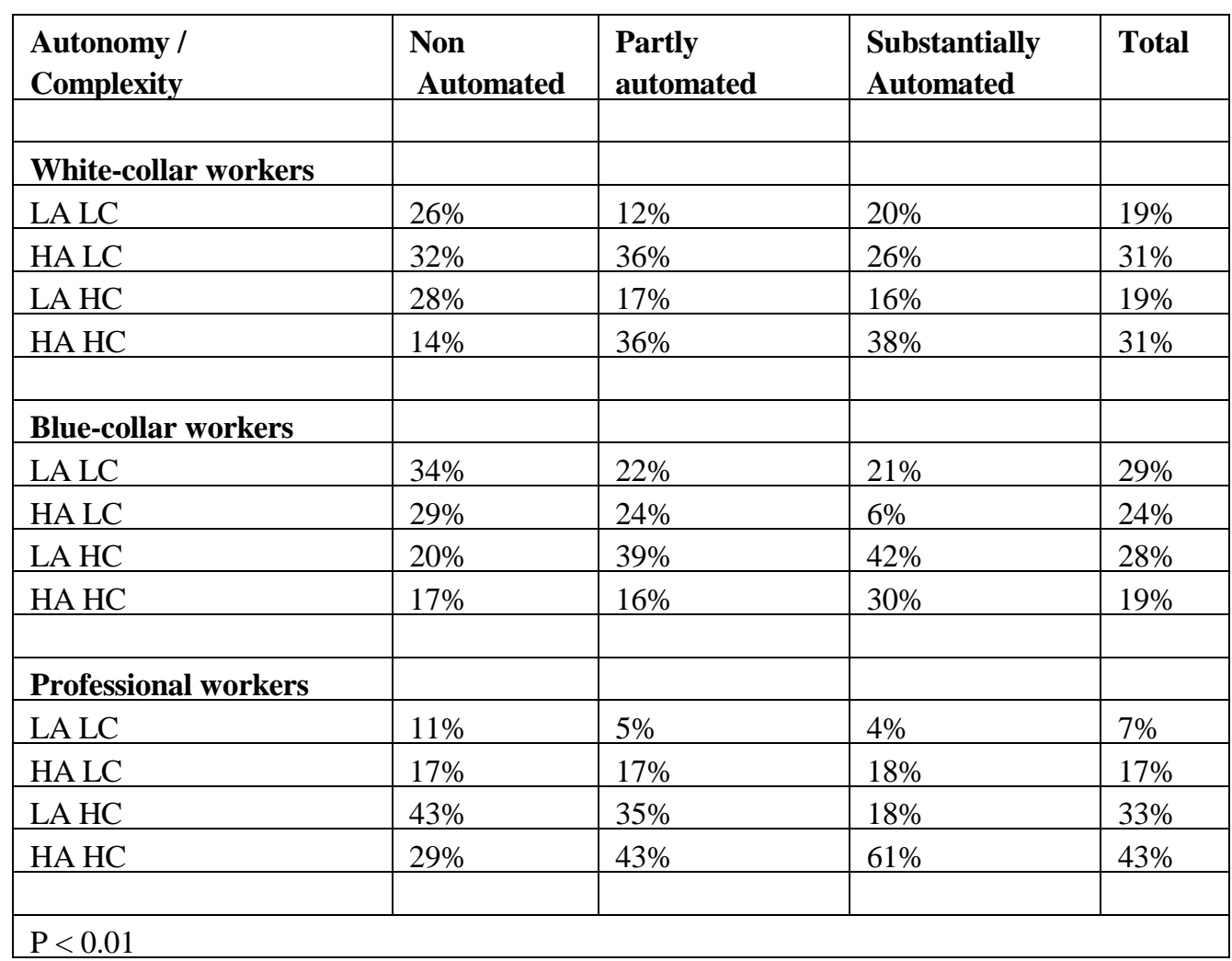

For white-collar workers: $n=264$, Cramer's V=.18, blue-collar workers: $n=212$, Cramer's V=.21, professional workers n=245, Cramer's V = .19 
Table 3 Regression analysis on the 'three utilisation gaps'

\begin{tabular}{|c|c|c|c|}
\hline \multirow[t]{2}{*}{ Independent variables } & \multicolumn{3}{|c|}{ dependent variables } \\
\hline & $\begin{array}{l}\text { credential } \\
\text { gap }\end{array}$ & $\begin{array}{l}\text { performance } \\
\text { gap }\end{array}$ & $\begin{array}{l}\text { development } \\
\text { gap }\end{array}$ \\
\hline & \multicolumn{3}{|l|}{ beta } \\
\hline Automated $(1=$ not $)$ & $.10^{*}$ & & \\
\hline \multicolumn{4}{|l|}{ Substantially automated (1=yes) } \\
\hline \multicolumn{4}{|l|}{ Gender (1=female) } \\
\hline Age & & $-.14 * *$ & $.20 * *$ \\
\hline Autonomy & $-.09 *$ & $-.13 * *$ & $-.22 * *$ \\
\hline Complexity & $-.22 * *$ & $-.42 * *$ & $-.36 * *$ \\
\hline Educational level attained & $.59 * *$ & $.17 * *$ & \\
\hline Internal differentiation (1=yes) & & $-.11 *$ & \\
\hline Blue-collar workers $(1=y e s)$ & $.19 * *$ & & \\
\hline \multirow{2}{*}{ Professional workers (1=yes) } & $-.21 * *$ & & \\
\hline & $\begin{array}{l}N=670 \\
R^{2}=0.27\end{array}$ & $\begin{array}{l}\mathrm{N}=685 \\
\mathrm{R}^{2}=0.22\end{array}$ & $\begin{array}{l}\mathrm{N}=685 \\
\mathrm{R}^{2}=0.29\end{array}$ \\
\hline
\end{tabular}


Table 4 Stepwise regression analysis of different independent variables on 'job satisfaction'

\begin{tabular}{|l|l|l|}
\hline Independent variables & Beta step 1 & Beta step 2 \\
\hline Automated (1=not) & & \\
\hline Substantially automated (1=yes) & & \\
\hline Gender (1=female) & & \\
\hline Age & $.23 * *$ & $.26 * *$ \\
\hline Autonomy & $.15 * *$ & \\
\hline Complexity & $.22 * *$ & \\
\hline Educational level attained & $-.10 * *$ & \\
\hline Internal differentiation & & \\
\hline Blue-collar workers $(1=y e s)$ & & \\
\hline Professional workers $(1=\mathrm{yes})$ & & \\
\hline & & $-.29 * *$ \\
\hline Development gap & & $-.17 * *$ \\
\hline Performance gap & & $\mathrm{ns}$ \\
\hline Credential gap & & \\
\hline & & \\
\hline & & \\
\hline & & \\
\hline & & \\
\hline N $=685 * \mathrm{p}<.05 * * \mathrm{p}<.01$ & & \\
\hline
\end{tabular}




\section{Notes}

${ }^{1}$ The question was posed as follows: In your job do you use automated devices such as terminals, word processors, personal computers, digital control devices, $\mathrm{CAD}$ or

$\mathrm{CAD} / \mathrm{CAM}, \mathrm{NC}$ or $\mathrm{CNC}$, robots, etc.? 0 no, 1 yes.

2 The autonomy scale consisted of nine items on which 'yes' or 'no' were the two possible answers. The scale included items such as 'Can you yourself postpone the moment a task should be completed?'; 'Can you easily leave your working place?'; 'Can you yourself decide when you do a task?', etc.

${ }^{3}$ The scale for complexity consisted of 11 items on which 'yes' or 'no' were the two possible answers. The scale included items such as 'Do you need to remember information for a long time?'; 'Does your work require constant concentration?'; 'Does your job almost entirely consist of difficult tasks?'

${ }^{4}$ To determine the cluster-membership of a job we perceived the classes I, II, and III of the well-known EGP class scheme to be 'white-collar'. The classes V, VI and VII were perceived as 'blue-collar'. Respondents with a job that can be seen as professional or semi-professional (according to Asping-Andersen) were placed within category five or six (Assimakopolou 1992).

${ }^{5}$ The scale consisted of four items on which 'yes' or 'no' were the two possible answers: 1. Do you learn new things in your work?; 2. Does your organisation offer you the chance to follow education or courses? 3 . Does your job increase your chances and possibilities on the labour market? 4. Does your job offer you possibilities for personal growth and development?

${ }^{6}$ This scale included items such as 'Have you in recent months thought about the possibility of looking for another job?'; 'The idea that I have to do my job until retirement frightens me?'; 'I love my job' The possible answers were always 'yes' or 'no'.

${ }^{7}$ These three kinds of jobs were exchanged for two dummy variables (in a later regression analysis): one for blue-collar workers $(=1)$ or not $(=0)$ and one for professionals $(=1)$ or not $(=0)$. 